\title{
Influence of Different Pigment Incorporation Methods on Color, Dimensional Stability, and Detail Reproduction of Silicones
}

\author{
Adhara Smith Nobrega ${ }^{1}$ Estefania Marrega Malavazi ${ }^{1}$ Clóvis Lamartine de Moraes Melo Neto ${ }^{1}$ \\ Isabela Caroline de Sousa Ervolino ${ }^{1}$ Lisiane Cristina Bannwart ${ }^{1}$ André Pinheiro de Magalhães Bertoz ${ }^{2}$ \\ Marcelo Coelho Goiato ${ }^{1}$
}

${ }^{1}$ Department of Dental Materials and Prosthodontics, School of Dentistry, São Paulo State University (Unesp), Araçatuba, São Paulo, Brazil

${ }^{2}$ Department of Pediatric and Social Dentistry, School of Dentistry, São Paulo State University (Unesp), Araçatuba, São Paulo, Brazil

Eur J Dent 2019;13:399-404

\begin{abstract}
Address for correspondence Marcelo Coelho Goiato, DDS, MSc, PhD, Department of Dental Materials and Prosthodontics, Aracatuba Dental School, Univ. Estadual Paulista-UNESP, José Bonifácio street, \#1193, Araçatuba, São Paulo, 16015-050, Brazil (e-mail: m.goiato@unesp.br).
\end{abstract}

\begin{abstract}
Keywords

- maxillofacial prosthesis

- silicone elastomers

- oncology

- physical properties

Objective To analyze the influence of three pigment incorporation methods on color change, dimensional stability, and detail reproduction of the MDX4-4210 and A-2186 silicones.

Materials and Methods The A-2186 and MDX4-4210 silicones were used for preparation of samples, with the incorporation of bronze, black and pink pigments, usingconventional, mechanical, and industrial incorporation methods. Samples were submitted to the initial readings of color ( $n=10 ; 22$-mm diameter $\times 2$-mm thickness), detail reproduction, and dimensional stability $(n=10 ; 30-\mathrm{mm}$ diameter $\times 3-\mathrm{mm}$ thickness). Readings were also taken at the end of 252, 504 and 1,008 hours of aging cycles. Results Quantitative data were evaluated by ANOVA and Tukey test, with a level of significance of $5 \%$. The mechanical and industrial methods caused smaller color changes of all samples compared with the conventional method $(p<0.05)$. In most cases, the mechanical and industrial methods caused less samples' contraction than the conventional method after aging $(p<0.05)$. The color change values increased progressively in each aging period for all samples $(p<0.05)$. The contraction values increased progressively in each aging period for all samples $(p<0.05)$. In the qualitative analysis of detail reproduction, all samples presented full reproduction of the three grooves, with accurate angles, initially and after the aging periods. Conclusions The industrial and mechanical methods showed the best results for color and dimensional stability. Despite the statistical differences, all pigment incorporation methods generated acceptable dimensional and color changes of the MDX4-4210 and A-2186 silicones, regardless of the pigment and aging. In addition, the detail reproduction was satisfactory after aging periods in all cases of this study, showing the excellent quality of the A-2186 and MDX4-4210 silicones.
\end{abstract}

\section{Introduction}

Maxillofacial prostheses are important for patients with orofacial defects. ${ }^{1-8}$ These prostheses protect the areas containing exposed tissues and satisfactorily represent an

DOI https://doi.org/

$10.1055 / \mathrm{s}-0039-1700768$

ISSN 1305-7456. alternative for esthetic recovery. ${ }^{9}$ In addition, they improve users' self-esteem and quality of life, allowing their reintegration into society. ${ }^{1,7,-11}$ Among the materials available for making maxillofacial prostheses, silicone elastomer is the most used option. ${ }^{1,2,4,7,9-11}$ 
Silicones are biocompatible, ${ }^{3,4,11}$ easy to manipulate, ${ }^{1,3,10,12}$ chemically inert, relatively strong, ${ }^{1,5}$ flexible, translucent, esthetic, light weight, ${ }^{11}$ comfortable, ${ }^{7,10}$ stable when exposed to heat, and repel water, blood, and organic materials. ${ }^{2,9}$

The deterioration of silicones usually occurs from 3 to 12 months after prosthesis fabrication. ${ }^{13}$ The silicone degradation is related to exposure to ultraviolet rays, air pollution, humidity, incorrect cleaning, and daily handling of the prostheses by patients., ${ }^{3,9,12}$ Color, dimensional stability and detail reproduction are properties directly related to the aesthetics of a facial prosthesis., ${ }^{7,114}$ Due to deterioration, color $^{13}$ and dimensional instability 2,7 of the silicone may occur. In addition, detail reproduction is another factor that must be evaluated after the deterioration of a silicone.

When pigments are added to silicones, changes in their physical and mechanical properties may occur. ${ }^{4-6,12,13}$ Additionally, the pigment incorporation method may influence the amount of bubbles formed within the material, and this may affect the properties of silicones..$^{15}$ In the literature, there is no information on the industrial method of pigment incorporation into the MDX4-4210 and A-2186 silicones. The MDX4-4210 and A-2186 silicones are elastomers widely used for facial rehabilitation, ${ }^{16}$ and their study is fundamental for dentistry. Therefore, the aim of this study was to analyze the influence of three pigment incorporation methods (conventional, mechanical and industrial) on color change, dimensional stability, and detail reproduction of the MDX44210 and A-2186 silicones, before and after aging.

\section{Materials and Methods}

The silicones A-2186 (A2) (Factor II, USA) and Silastic MDX44210 (MDX) (Dow Corning Corporation Medical Products, USA) were used in this study. These silicones were distributed according to the intrinsic pigment (black, bronze and pink) added to them, the incorporation method (conventional or manual, mechanical, and industrial), and the tests to be performed (color and dimensional stability/detail reproduction).

The pigments bronze (Tan FI - 215, Factor II, USA) and black (Black FI - 205, Factor II, USA) are commercially available. The new medium pink pigment (Orbital Colors, Orbital Ind. e Com. Ltd, Brazil) was also tested in this study. For sample preparation, the silicones and pigments were weighed on a digital analytical balance (Adventurer, Ohaus Corporation, USA). ${ }^{9}$ Each pigment from Factor II corresponded to $0.2 \%$ of the weight of its respective silicone. ${ }^{2,6}$ For the pink pigment, the pigments that constituted it corresponded to $0.122 \%$ (yellow), $0.006 \%$ (black), $0.03 \%$ (red), and $0.6 \% \mathrm{TiO}_{2}$ (white) of the silicone weight. All tested pigments had an organic origin and the white opacifier $\left(\mathrm{TiO}_{2}\right.$ ) had a mineral origin.

Regarding the pigment incorporation, in the conventional method, the pigment was mixed with the silicone on a glass plate by using a stainless-steel spatula, until obtaining a homogeneous mass. The silicone was handled at a controlled temperature of $23 \pm 2^{\circ} \mathrm{C}^{2,7,9,14}$ After the manipulation, the silicone was inserted into the matrix and the thickness was regularized with the aid of a metal spatula. Subsequently, the silicone contained in the matrix was exposed to the environment for 72 hours until complete polymerization of the material. ${ }^{9}$ The samples were carefully separated from the matrix. ${ }^{9}$

For the mechanical incorporation, the silicone was manually mixed with the pigment for 15 seconds, followed by a mechanical vacuum spatulation (15 pounds) for 10 minutes at 425 RPM (Model 1170/97, Polidental Ind. e Com. Ltda, Brazil). Then, the silicone was inserted into the matrix, following the same procedure as the conventional method.

The industrial incorporation of pigment to the silicone was performed using a grinding machine (CHSG/3-Roll Mill, Chemieland, China). The material quality control test was performed according to the Deutsches Institut für Normung (DIN - 53235) standard. Subsequently, the silicone was inserted into the matrix, following the same procedure as the conventional method.

Samples were submitted to the initial readings of color stability $(n=10 ; 22$-mm diameter $\times 2$-mm thickness $),{ }^{17}$ detail reproduction, and dimensional stability $(n=10 ; 30-\mathrm{mm}$ diameter $\times 3$-mm thickness). ${ }^{2,7}$ Then, samples were aged for 252,504 , and 1,008 hours, $2,6,7,13$ and new readings were taken at the end of each aging cycle.

Color stability readings were obtained using a spectrophotometer of visible ultraviolet reflection (UV-2450, Shimadzu, Japan). Color changes $(\Delta \mathrm{E})$ were calculated using the CIELab System, as established by Commission Internationale de I'Eclairage (CIE; International Commission on Illumination). This system can be calculated according to the formula: $\Delta \mathrm{E}=\left[(\Delta \mathrm{L})^{2}+(\Delta \mathrm{a})^{2}+(\Delta \mathrm{b})^{2}\right]^{1 / 2} \cdot 3,12,13,15,17-22$ The coordinate "a" represents the amount of red (positive values) and green (negative values), while coordinate "b" represents the amount of yellow (positive values) and blue (negative values). ${ }^{6}$

For the dimensional stability analysis, samples were scanned using an 800 dpi-resolution scanner (Genius, Germany). To standardize the measurement, a metallic block with two vertical lines $25 \mathrm{~mm}$ apart was scanned with each sample. Measurements were performed using the AutoCAD 2018 software (R16 version N63.0, Autodesk, Inc., USA). Scan images were imported into the software using the "Raster image" tool. ${ }^{714}$ Each sample was measured three times, and the following formula was applied (\%): $(B-A) / A \times 100$ $(\mathrm{A}=$ distance between block lines $=25 \mathrm{~mm}$; $\mathrm{B}=$ distance between the lines of the sample). ${ }^{2,7,8,14}$

For the detail reproduction analysis, the angular accuracy of three grooves (20-, 50-, and $75 \mu \mathrm{m}$-wide) were evaluated in each sample using a stereoscopic (Olympus, Japan) with low-angle illumination and 13X magnification. The detail reproduction evaluation was performed according to Goiato et al: score X-no groove reproduction; score 0 -full reproduction of two of the three grooves; score 1-full reproduction of the 3 grooves with inaccurate angles; score 2-full reproduction of the 3 grooves with accurate angles. ${ }^{7,8,14}$

For the accelerated aging, samples were placed in an accelerated aging chamber (Equilam, Brazil). The samples were subjected to alternating periods of ultraviolet light and condensation using oxygen-saturated distilled water under the conditions of heat and $100 \%$ humidity. Each aging cycle was 
performed for 12 hours. In the first 8 hours, the ultraviolet light was imputed onto the samples and the temperature was at $60 \pm 3^{\circ} \mathrm{C}$. In the last 4 hours, the temperature was at $45 \pm$ $3^{\circ} \mathrm{C}$ and the condensation period occurred without light. This test was performed for a total of 1,008 hours., ${ }^{2,3,6,9,10,13}$ Readings were taken after 252, 504 and 1,008 hours of accelerated aging. $2,6,10,13$

Quantitative data were analyzed using analysis of variance (ANOVA) and Tukey test, with a level of significance of 5\%. For the detail reproduction analysis, qualitative scores recommended by Goiato et al were followed. ${ }^{7,8,14}$

\section{Results}

The samples manufactured by the mechanical and industrial methods presented the lowest $\Delta \mathrm{E}$ values $(p<0.05)$, regardless of the silicone type and pigment color $(-$ Table $\mathbf{1})$.

The accelerated aging produced a progressive increase in the color values of all samples, regardless of the silicone, pigment color, and incorporation method, with statistically significant difference among periods. - Table 2 shows only the industrial incorporation method; however, the samples of the other two methods also showed a significant progressive increase $(p<0.05)$ in the color values in each aging period with $\Delta \mathrm{E}<3.7$, regardless of the silicone and pigment.

In most cases, the MDX and $\mathrm{A} 2$ silicones manufactured by the mechanical and industrial methods showed less contraction than the silicones (MDX and A2) manufactured by the conventional method after aging $(p<0.05)$ (-Tables 3 ). The accelerated aging produced a progressive increase in the contraction values of all samples (\%) regardless of the silicone, pigment, and incorporation method, with statistically significant difference among periods $(p<0.05)(-$ Tables 3 and 4 ). - Table 4 shows only the industrial incorporation method; however, the samples of the other two methods also showed significant $(p<0.05)$ progressive contraction in each aging period $(<0.4 \%)$, regardless of the silicone and pigment.

In the qualitative analysis of detail reproduction, all samples showed a score of 2 before and after 252, 504, and 1,008 hours of accelerated aging.

\section{Discussion}

Color change is one of the causes for replacement of maxillofacial prostheses. ${ }^{6}$ The results of the present study indicated that the mechanical and industrial methods were the most favorable methods for color stability (-Table 1). Probably, this result happened due to a more homogeneous mixture between silicone and pigment, reducing the oxygen incorporation into the material.

In the present study, there was a progressive increase in the color change values after aging periods for all samples. This can have happened because most polymers contain aromatic rings and $\mathrm{C}=\mathrm{C}$ bonds in their structures. Aromatic rings and $\mathrm{C}=\mathrm{C}$ bonds can absorb ultraviolet rays during accelerated aging. ${ }^{7}$ According to Goiato et al and Nobrega et al, when a polymer molecule absorbs ultraviolet light, this energy promotes instability in the molecular structure. The excess

Table 1 Mean values (standard deviation) of color alteration $(\Delta \mathrm{e})$ of the silicones used according to the incorporation method, pigment, and silicone brand

\begin{tabular}{|l|l|l|l|l|}
\hline Silicone & Pigment & Incorporation method & \multicolumn{2}{l|}{} \\
\cline { 2 - 5 } & & Conventional & Mechanical & Industrial \\
\hline \multirow{3}{*}{ A2 } & Bronze & $2.01(0.09) \mathrm{a}$ & $1.40(0.10) \mathrm{b}$ & $1.41(0.18) \mathrm{b}$ \\
\cline { 2 - 5 } & Black & $2.16(0.66) \mathrm{a}$ & $1.55(0.26) \mathrm{b}$ & $1.38(0.14) \mathrm{b}$ \\
\cline { 2 - 5 } & Pink & $1.25(0.17) \mathrm{a}$ & $0.81(0.08) \mathrm{b}$ & $0.57(0.11) \mathrm{b}$ \\
\hline \multirow{3}{*}{ MDX } & Bronze & $1.93(0.99) \mathrm{a}$ & $1.54(0.31) \mathrm{b}$ & $1.42(0.19) \mathrm{b}$ \\
\cline { 2 - 5 } & Black & $3.63(0.49) \mathrm{a}$ & $2.08(0.10) \mathrm{b}$ & $2.06(0.09) \mathrm{b}$ \\
\cline { 2 - 5 } & Pink & $1.50(0.19) \mathrm{a}$ & $0.93(0.08) \mathrm{b}$ & $0.64(0.12) \mathrm{b}$ \\
\hline
\end{tabular}

Note: Tukey test with a level of significance of $5 \%$. Different letters in the row indicate a statistically significant difference $(p<0.05)$.

Table 2 Mean values (standard deviation) of color alteration $(\Delta \mathrm{e})$ of the silicones used that received industrial incorporation of pigments, according to the pigment, silicone, and different periods of analysis

\begin{tabular}{|l|l|l|l|l|}
\hline Silicone & Pigment & Period & \multicolumn{2}{|l|}{} \\
\cline { 2 - 5 } & & 252 hours & 504 hours & 1008 hours \\
\hline \multirow{4}{*}{ A2 } & Bronze & $0.81(0.11) a$ & $1.27(0.26) \mathrm{b}$ & $1.41(0.18) \mathrm{c}$ \\
\cline { 2 - 5 } & Black & $0.51(0.13) \mathrm{a}$ & $0.94(0.21) \mathrm{b}$ & $1.38(0.14) \mathrm{c}$ \\
\cline { 2 - 5 } & Pink & $0.28(0.10) \mathrm{a}$ & $0.40(0.13) \mathrm{b}$ & $0.57(0.11) \mathrm{c}$ \\
\hline \multirow{3}{*}{ MDX } & Bronze & $0.38(0.04) \mathrm{a}$ & $0.51(0.09) \mathrm{b}$ & $1.42(0.19) \mathrm{c}$ \\
\cline { 2 - 5 } & Black & $0.31(0.06) \mathrm{a}$ & $0.67(0.18) \mathrm{b}$ & $2.06(0.09) \mathrm{c}$ \\
\cline { 2 - 5 } & Pink & $0.20(0.04) \mathrm{a}$ & $0.37(0.14) \mathrm{b}$ & $0.64(0.12) \mathrm{c}$ \\
\hline
\end{tabular}

Note: Tukey test with a level of significance of $5 \%$. Different letters in the row indicate a statistically significant difference $(p<0.05)$. 
Table 3 Mean values (standard deviation) of dimensional stability (\%) of the silicones used, according to the pigment, incorporation method, and different periods of analysis

\begin{tabular}{|c|c|c|c|c|}
\hline \multirow[t]{2}{*}{ Silicone } & \multirow[t]{2}{*}{ Pigment } & \multirow[t]{2}{*}{ Incorporation method } & \multicolumn{2}{|c|}{ Period } \\
\hline & & & Initial & 1008 hours \\
\hline \multirow[t]{9}{*}{ A2 } & \multirow[t]{3}{*}{ Bronze } & Conventional & $0.19(0.02) \mathrm{Aa}$ & $0.34(0.04) \mathrm{Ab}$ \\
\hline & & Mechanical & $0.18(0.03) \mathrm{Aa}$ & $0.29(0.02) \mathrm{Bb}$ \\
\hline & & Industrial & $0.15(0.04) \mathrm{Ba}$ & $0.28(0.02) \mathrm{Bb}$ \\
\hline & \multirow[t]{3}{*}{ Black } & Conventional & $0.23(0.02) \mathrm{Aa}$ & $0.34(0.05) \mathrm{Ab}$ \\
\hline & & Mechanical & $0.21(0.04) \mathrm{Aa}$ & $0.33(0.04) \mathrm{Ab}$ \\
\hline & & Industrial & $0.16(0.05) \mathrm{Ba}$ & $0.32(0.05) \mathrm{Ab}$ \\
\hline & \multirow[t]{3}{*}{ Pink } & Conventional & $0.16(0.03) \mathrm{Aa}$ & $0.27(0.04) \mathrm{Ab}$ \\
\hline & & Mechanical & $0.12(0.03) \mathrm{Ba}$ & $0.24(0.03) \mathrm{Bb}$ \\
\hline & & Industrial & $0.10(0.03) \mathrm{Ba}$ & $0.22(0.05) \mathrm{Bb}$ \\
\hline \multirow[t]{9}{*}{ MDX } & \multirow[t]{3}{*}{ Bronze } & Conventional & $0.21(0.04) \mathrm{Aa}$ & $0.35(0.05) \mathrm{Ab}$ \\
\hline & & Mechanical & $0.21(0.04) \mathrm{Aa}$ & $0.30(0.03) \mathrm{Bb}$ \\
\hline & & Industrial & $0.18(0.04) \mathrm{Ba}$ & $0.30(0.03) \mathrm{Bb}$ \\
\hline & \multirow[t]{3}{*}{ Black } & Conventional & $0.26(0.03) \mathrm{Aa}$ & $0.36(0.04) \mathrm{Ab}$ \\
\hline & & Mechanical & $0.24(0.02) \mathrm{ABa}$ & $0.34(0.03) \mathrm{Ab}$ \\
\hline & & Industrial & $0.22(0.04) \mathrm{Ba}$ & $0.37(0.04) \mathrm{Ab}$ \\
\hline & \multirow[t]{3}{*}{ Pink } & Conventional & $0.17(0.04) \mathrm{Aa}$ & $0.34(0.03) \mathrm{Ab}$ \\
\hline & & Mechanical & $0.16(0.03) \mathrm{Aa}$ & $0.24(0.04) \mathrm{Bb}$ \\
\hline & & Industrial & $0.14(0.03) \mathrm{Aa}$ & $0.26(0.03) \mathrm{Bb}$ \\
\hline
\end{tabular}

Note: Tukey test with a level of significance of $5 \%$. Different uppercase letters in the column denote a statistically significant difference (for each pigment of each silicone individually) $(p<0.05)$. Different lowercase letters in the row denote a statistically significant difference $(p<0.05)$.

Table 4 Mean values (standard deviation) of dimensional stability (\%) of the silicones used that received industrial incorporation of pigments, according to the pigment, silicone, and different periods of analysis

\begin{tabular}{|l|l|l|l|l|l|}
\hline \multirow{2}{*}{ Silicone } & \multirow{2}{*}{ Pigment } & \multicolumn{4}{|c|}{ Period } \\
\cline { 3 - 6 } & & Initial & 252 hours & 504 hours & 1008 hours \\
\hline \multirow{3}{*}{ A2 } & Bronze & $0.15(0.04) \mathrm{a}$ & $0.20(0.03) \mathrm{b}$ & $0.22(0.02) \mathrm{c}$ & $0.28(0.02) \mathrm{d}$ \\
\cline { 2 - 6 } & Black & $0.16(0.05) \mathrm{a}$ & $0.19(0.05) \mathrm{b}$ & $0.25(0.05) \mathrm{c}$ & $0.32(0.05) \mathrm{d}$ \\
\cline { 2 - 6 } & Pink & $0.10(0.03) \mathrm{a}$ & $0.14(0.03) \mathrm{b}$ & $0.17(0.04) \mathrm{c}$ & $0.22(0.05) \mathrm{d}$ \\
\hline \multirow{3}{*}{ MDX } & Bronze & $0.18(0.04) \mathrm{a}$ & $0.21(0.04) \mathrm{b}$ & $0.24(0.03) \mathrm{c}$ & $0.30(0.03) \mathrm{d}$ \\
\cline { 2 - 6 } & Black & $0.22(0.04) \mathrm{a}$ & $0.25(0.05) \mathrm{b}$ & $0.29(0.05) \mathrm{c}$ & $0.37(0.04) \mathrm{d}$ \\
\cline { 2 - 6 } & Pink & $0.14(0.03) \mathrm{a}$ & $0.16(0.03) \mathrm{b}$ & $0.20(0.03) \mathrm{c}$ & $0.26(0.03) \mathrm{d}$ \\
& & & & &
\end{tabular}

Note: Tukey test with a level of significance of $5 \%$. Different letters in the row indicate a statistically significant difference $(p<0.05)$.

energy can be transmitted by excitation from one molecule to another, allowing the first molecule to regain its stability. In this way, affected groups can return to their original state by releasing energy in the form of longer wavelengths such as visible light or heat. However, when this excess energy is released, a photochemical degradation occurs, contributing to molecule degradation. This can be evidenced by changes in the color and brightness of a material. ${ }^{79}$ Additionally, according to Goiato et al, this set of events can also explain the dimensional changes of a silicone. ${ }^{7}$

According to the literature, a $\Delta \mathrm{E} \leq 3.7$ is considered acceptable for the color change of a material. ${ }^{23-25}$ The highest value found for chromatic alteration was for the black pigment (3.63) incorporated by conventional method to the MDX silicone ( - Table 1). Therefore, all groups of the three incorporation methods showed acceptable color stability.

All dimensional values of this study exhibited a significant progressive increase after aging periods, indicating a contraction of the materials ( $\mathbf{- T a b l e s} \mathbf{3}$ and $\mathbf{4}$ ). Five factors are responsible for dimensional changes in silicones: thermal shrinkage due to temperature changes; polymerization shrinkage by product release during condensation reactions; sorption after exposure to water; disinfectants or high humidity environments for long periods; and incomplete elastic deformation 
recovery due to viscoelastic behavior. ${ }^{2}$ The accelerated aging used in this study involved ultraviolet rays, temperature changes, and humidity. Ultraviolet rays may be associated with the polymerization of a silicone. ${ }^{9}$ Therefore, these factors may have contributed to the dimensional changes of the samples. Despite the silicones contraction in all groups after aging periods, this situation is within the parameters recommended by ISO $4823{ }^{7}$ According to this recommendation, the contraction must not be greater than $1.5 \%$ after 24 hours. In the present study, the values found after 1,008 hours of aging were less than $0.4 \%$.

In most cases, the silicones manufactured by the industrial and mechanical methods showed greater dimensional stability (less contraction) than silicones manufactured by the conventional method after aging. This is probably also related to a more homogeneous mixture between silicone and pigment. In this study, the industrial and mechanical methods showed the best results for color and dimensional stability. However, the industrial method requires a grinding machine, DIN quality control, and qualified professionals. This can increase the manufacturing time and cost of a prosthesis. Therefore, the mechanical method could be cheaper and faster for the rehabilitation of a patient.

Regarding the detail reproduction, all groups showed a score of 2, regardless of the incorporation method, pigment, silicone, and period. According to Goiato et al, a score of 2 indicates that all samples had a full reproduction of the three grooves with accurate angles. ${ }^{2,7,8,14}$ These findings, according to some studies, verified that facial silicones had excellent detail reproduction capacity, reproducing grooves of up to $20 \mu \mathrm{m}$ wide. ${ }^{2,7,8,14}$

\section{Conclusions}

The industrial and mechanical methods showed the best results for color and dimensional stability. Despite the statistical differences, all pigment incorporation methods generated acceptable dimensional and color changes of the MDX4 -4210 and A-2186 silicones, regardless of the pigment and aging. In addition, the detail reproduction was satisfactory after aging periods in all cases of this study, showing the excellent quality of the A-2186 and MDX4-4210 silicones.

\section{Authors' Contributions}

Adhara Smith Nobrega: Involved in study design, made the specimens, performed the tests, wrote the article, and reviewed the article.

Estefania Marrega Malavazi: Prepared the specimens and reviewed the article.

Clóvis Lamartine de Moraes Melo Neto: Involved in study design, realized statistics, and reviewed the article.

Isabela Caroline de Sousa Ervolino: Performed the tests, wrote the article, and reviewed the article.

Lisiane Cristina Bannwart: Involved in study design, realized statistics, and reviewed the article.

André Pinheiro de Magalhães Bertoz: Realized statistics, wrote the article, and reviewed the article.

Marcelo Coelho Goiato: Involved in study design and reviewed the article.

\section{Conflict of Interest}

None declared.

\section{References}

1 Rai SY, Guttal SS. Effect of intrinsic pigmentation on the tear strength and water sorption of two commercially available silicone elastomers. J Indian Prosthodont Soc 2013;13(1):30-35

2 Haddad MF, Goiato MC, Dos Santos DM, Pesqueira AA, Moreno A, Pellizzer EP. Influence of pigment and opacifier on dimensional stability and detail reproduction of maxillofacial silicone elastomer. J Craniofac Surg 2011;22(5):1612-1616

3 Cevik P, Yildirim-Bicer AZ. Effect of different types of disinfection solution and aging on the hardness and colour stability of maxillofacial silicone elastomers. Int J Artif Organs 2017 doi: 10.5301/ijao.5000659

4 Cevik P, Eraslan O. Effects of the addition of titanium dioxide and silaned silica nanoparticles on the mechanical properties of maxillofacial silicones. J Prosthodont 2017;26(7):611-615

5 Nguyen CT, Chambers MS, Powers JM. Kiat-Amnuay S. Effect of opacifiers and UV absorbers on pigmented maxillofacial silicone elastomer, part 2: mechanical properties after artificial aging. J Prosthet Dent 2013;109(6):402-410

6 dos Santos DM, Goiato MC, Moreno A, Pesqueira AA, Haddad MF. Influence of pigments and opacifiers on color stability of an artificially aged facial silicone. J Prosthodont 2011;20(3):205-208

7 Goiato MC, Haddad MF, Sinhoreti MA, dos Santos DM, Pesqueira AA, Moreno A. Influence of opacifiers on dimensional stability and detail reproduction of maxillofacial silicone elastomer. Biomed Eng Online 2010;9:85

8 Goiato MC, Pesqueira AA, dos Santos DM, Antenucci RM, Ribeiro Pdo. Evaluation of dimensional change and detail reproduction in silicones for facial prostheses. Acta Odontol Latinoam 2008;21(1):85-88

9 Nobrega AS, Andreotti AM, Moreno A. Sinhoreti MA, Dos Santos DM, Goiato MC. Influence of adding nanoparticles on the hardness, tear strength, and permanent deformation of facial silicone subjected to accelerated aging. J Prosthet Dent 2016;116(4):623-62

10 Goiato MC, Haddad MF, Santos DM, Pesqueira AA, Moreno A. Hardness evaluation of prosthetic silicones containing opacifiers following chemical disinfection and accelerated aging. Braz Oral Res 2010;24(3):303-308

11 Seçilmiş A, Oztürk AN. Nasal prosthesis rehabilitation after partial rhinectomy: a clinical report. Eur J Dent 2007;1(2):115-118

12 Han Y, Powers JM, Kiat-Amnuay S. Effect of opacifiers and UV absorbers on pigmented maxillofacial silicone elastomer, part 1: color stability after artificial aging. J Prosthet Dent 2013;109(6):397-401

13 dos Santos DM, Goiato MC, Sinhoreti MA, Fernandes AU, Ribeiro Pdo, Dekon SF. Color stability of polymers for facial prosthesis. J Craniofac Surg 2010;21(1):54-58

14 Pesqueira AA, Goiato MC, Dos Santos DM, Haddad MF, Moreno A. Effect of disinfection and accelerated ageing on dimensional stability and detail reproduction of a facial silicone with nanoparticles. J Med Eng Technol 2012;36(4):217-221

15 Hatamleh MM, Watts DC. Porosity and color of maxillofacial silicone elastomer. J Prosthodont 2011;20(1):60-66

16 Lai JH, Hodges JS. Effects of processing parameters on physical properties of the silicone maxillofacial prosthetic materials. Dent Mater 1999;15(6):450-455

17 Kiat-Amnuay S, Lemon JC, Powers JM. Effect of opacifiers on color stability of pigmented maxillofacial silicone A-2186 subjected to artificial aging. J Prosthodont 2002;11 (2):109-116 
18 Mancuso DN, Goiato MC, Zuccolotti BC, Moreno A, dos Santos DM, Pesqueira AA. Effect of thermocycling on hardness, absorption, solubility and colour change of soft liners. Gerodontology 2012;29(2):e215-e219

19 Beltrami R, Ceci M, De Pani G, et al. Effect of different surface finishing/polishing procedures on color stability of esthetic restorative materials: A spectrophotometric evaluation. Eur J Dent 2018;12(1):49-56

20 Ceci M, Viola M, Rattalino D, Beltrami R, Colombo M, Poggio C. Discoloration of different esthetic restorative materials: A spectrophotometric evaluation. Eur J Dent 2017;11(2):149-156

21 Ergun G, Nagas IC. Color stability of silicone or acrylic denture liners: an in vitro investigation. Eur J Dent 2007;1(3):144-151
22 Silva VDD, Dias C, Osório LB, Matje PRB, Menezes LM, Lima EMS. Color changes of esthetic elastomeric ligatures evaluated with the Commission Internationale d'Éclairage color system. Eur J Dent 2018;12(3):428-433

23 Imirzalioglu P, Karacaer O, Yilmaz B. Ozmen Msc I. Color stability of denture acrylic resins and a soft lining material against tea, coffee, and nicotine. J Prosthodont 2010;19(2):118-124

24 Johnston WM, Kao EC. Assessment of appearance match by visual observation and clinical colorimetry. J Dent Res 1989;68(5):819-822

25 Goiato MC, Nóbrega AS, dos Santos DM, Andreotti AM, Moreno A. Effect of different solutions on color stability of acrylic resin-based dentures. Braz Oral Res 2014;28(4):1-7 